\title{
Development and Simulation of Decentralised Water and Energy Supply Concepts - Case Study of Rainwater Harvesting at the Angkor Centre for Conservation of Biodiversity in Cambodia
}

\author{
Joel Czarny"1, Alexander Präbst ${ }^{2}$, Markus Spinnler ${ }^{3}$, Katja Biek $^{4}$, \\ Thomas Sattelmayer ${ }^{5}$ \\ ${ }^{1}$ BAnTec GmbH, Badenallee 1, Berlin, Germany \\ e-mail: joel-czarny@web.de \\ ${ }^{2}$ Lehrstuhl für Thermodynamik, Technische Universität München, Boltzmannstr. 15, \\ Garching, Germany \\ e-mail: praebst@td.mw.tum.de \\ ${ }^{3}$ Lehrstuhl für Thermodynamik, Technische Universität München, Boltzmannstr. 15, \\ Garching, Germany \\ e-mail: spinnler@td.mw.tum.de \\ ${ }^{4}$ Beuth Hochschule für Technik Berlin, Luxemburger Str. 9, Berlin, Germany \\ e-mail: biek@beuth-hochschule.de \\ ${ }^{5}$ Lehrstuhl für Thermodynamik, Technische Universität München, Boltzmannstr. 15, \\ Garching, Germany \\ e-mail: sattelmayer@td.mw.tum.de
}

\begin{abstract}
Cite as: Czarny, J., Präbst, A., Spinnler, M., Biek, K., Sattelmayer, T., Development and Simulation of Decentralised Water and Energy Supply Concepts - Case Study of Rainwater Harvesting at the Angkor Centre for Conservation of Biodiversity in Cambodia, J. sustain. dev. energy water environ. syst., 5(4), pp 626-644, 2017,
\end{abstract} DOI: http://dx.doi.org/10.13044/j.sdewes.d5.0171

\begin{abstract}
Besides a sufficient energy supply, concepts for accommodations require an intelligent water management. Using the example of quarters that do not have water and energy access, a dynamic simulation model is presented in which a rainwater harvesting concept is implemented and simulated over one year using MATLAB-Simulink. The aim is to minimize respectively suspend the use of fossil energy sources and to guarantee the provision of decentralized clean drinking water. Since traditional water bodies, e.g. groundwater, are increasingly polluted and depleted, utilisation of alternative sources is prudent. Especially in rural areas, where access to drinking water is scarce, rainwater is suitable for providing potable water. Besides its beneficial chemical water properties, it is easily accessed in a decentralized manner, which makes it a preferred choice in areas with sufficient precipitation. However, access to rainwater is limited by its occurrence and contamination, calling for proper storage, utilisation, and treatment strategies. For this purpose, a rainwater harvesting system, including different water and energy management systems, was modelled and implemented using the site of the Angkor Centre for Conservation of Biodiversity in Cambodia as an example. For the simulation, a precipitation generator was implemented using real historical rain event data. An appropriate rainwater treatment process was chosen, consisting of a microfiltration and a subsequent ultrafiltration unit removing bacteriological loads entirely. Both were modelled and implemented dynamically. Using the site of the Angkor Centre of Conservation of Biodiversity, a complete rainwater harvesting plant was implemented including harvest, storage, and utilization of rainwater. Further, a renewable energy
\end{abstract}

\footnotetext{
* Corresponding author
} 
management strategy is developed, using photovoltaic modules and batteries. It was shown that the cumulative runoff meets the water demand of the Angkor Centre for Conservation of Biodiversity and that the energy demand of the rainwater system as well as the site can be met by the installed photovoltaics on the existing roof area.

\section{KEYWORDS}

Rainwater harvesting, Precipitation generator, Membrane filtration, Decentralized energy management, MATLAB, Simulink.

\section{INTRODUCTION}

"Water is not a commercial product like any other but, rather a heritage which must be protected, defended, and treated as such [1]". On this account, traditional water bodies throughout the globe, such as groundwater and lakes, which are increasingly polluted and depleted due to industrialisation and rising drought intensities, need to be treated with care. Next to technologies focussing on the conservation, reclamation, natural infiltration, and reuse of water, Rainwater Harvesting (RWH) increasingly attracts notice. It is recognised as a sustainable method to overcome water scarcity in rural and urban areas and current environmental issues related to the hydrological cycle by closing it [2]. RWH not only provides water for human purposes, be it potable or non-potable, but also supports the recharge of traditional water sources as well as flood control in highly dense urban areas. However, access to rainwater is limited and its occurrence is often not accurately predictable, being one of the main barriers for the utilization of rainwater. This barrier can be overcome by implementing reservoirs with sufficient water capacity levels. Especially in areas where access to clean water is limited or non-existing, clean water can easily be provided in a decentralised manner [3]. RWH is the ideal solution in areas where the amount of precipitation is sufficient but groundwater supply is not, where surface water sources are either lacking or insufficient, or in decentralised areas not connected to centralised water distribution systems [4].

When tackling RWH, most studies either focus on the quality of the rainwater itself, the influence of the system parts, such as roofing, distribution, or storage material, or the general possibility of applying RWH. In this study, however, all these topics are combined in order to determine the potential of possible RWH systems. Moreover, most rainwater utilisation studies focus on the provision of non-palatable water. In the course of this work a RWH model is developed for the provision of drinking water which is driven by solar power, e.g. Photovoltaic (PV). The model consists of the generation of meaningful weather scenarios and the PV driven RWH system model, implemented in MATLAB and Simscape/Simulink [5], including a treatment system. The Cambodian Angkor Centre for Conservation of Biodiversity (ACCB) serves as the case study object. Its site characteristics, installed PV power, building measurements, and water demand characteristics are incorporated into the model. The potential of PV driven RWH at the ACCB is determined over a simulation period of one year.

\section{OVERVIEW OF CASE STUDY LOCATION AND WATER QUALITY CONSIDERATIONS}

In this section, the $\mathrm{ACCB}$ is introduced. Further, rainwater runoff quality considerations are made being the basis of the suggested treatment system.

\section{Description of Angkor centre for conservation for biodiversity case study}

ACCB [6] is the origin of the examination at hand. It is an animal rescue centre located in the Phnom Kulen National Park, $42 \mathrm{~km}$ north of Siem Reap, Cambodia. The average annual precipitation height is $1,334.77 \mathrm{~mm} / \mathrm{yr}$ [7] and the average annual irradiation is $1,900 \mathrm{kwh} / \mathrm{m}^{2} \mathrm{yr}$ [8]. The ACCB is a non-governmental organization 
focusing on rescuing selective native Cambodian wildlife and providing adequate rehabilitation and release facilities. Further, education and training programs are conducted for communities and wildlife officials. It consists of six buildings for living, offices, and animal related duties [9].

\section{Rainwater runoff quality considerations}

Prior to the development of the RWH system, water quality tests were conducted at different locations on site. There, the water quality was evaluated based on physicochemical parameters and ion concentrations. Additionally, a literature search was conducted in order to estimate the microbiological contamination as well as to compare the results of the tests with other test series.

Before the actual discussion of the rainwater runoff quality, possible factors influencing the quality are viewed in detail. Figure 1 depicts the influence of pollution sources on the water quality.

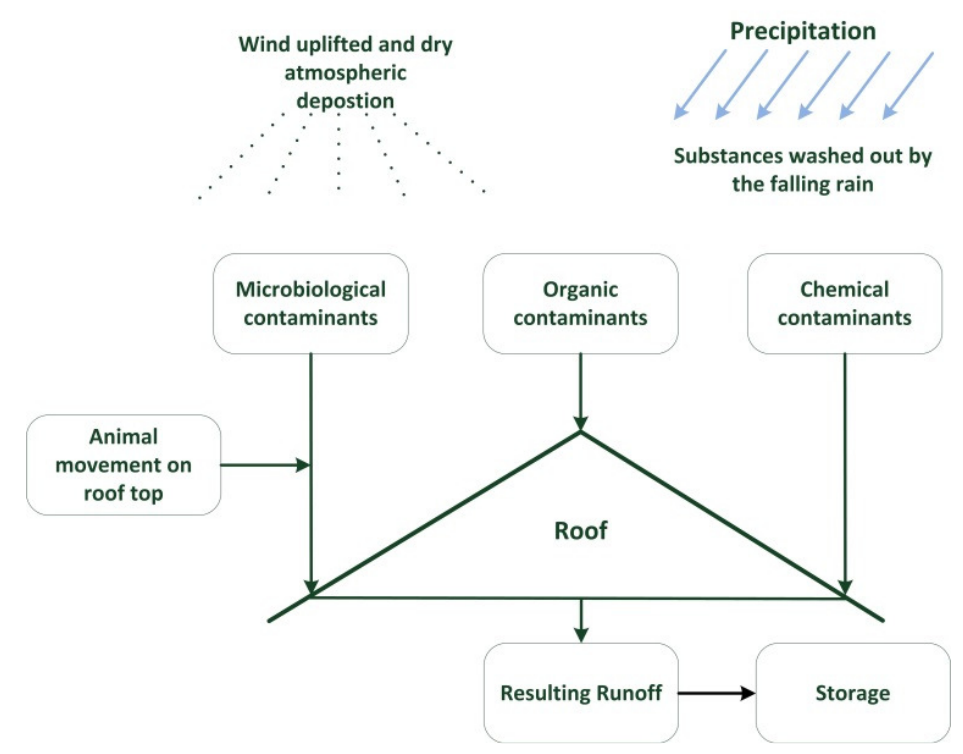

Figure 1. Schematic illustration of external pollution sources influencing the water quality of a RWH system, adapted from [4]

Atmospheric deposition and spatial conditions. Atmospheric deposition of physicochemical parameters, organic pollutants and microbial contamination in rainwater describes how and which particles in the atmosphere are dissolved by rainwater [10]. Their distribution in the atmosphere depends on the spatial conditions [11]. While cities for example tend to release considerable amounts of dust particles from combustion processes, pesticides are more commonly released in areas with high agricultural use [12]. Microbial contamination of the atmosphere is unique to the deposition of environmental organisms and strongly dependent on spatial conditions [13].

Generally, with increasing rainfall depth and duration, a decrease of all ionic components as well as a decrease of the $\mathrm{pH}$-value was observed [14]. It is believed that the acidity of the rainwater is, amongst others, closely related to the carbon dioxide concentration in the atmosphere since the atmosphere is in a chemical equilibrium with carbon dioxide. In the vicinity of highly industrialized areas the amount of produced carbon dioxide is high, resulting in more acid rain $[15,16]$.

Roof and distribution characteristics. The first part of the RWH system, which is in contact with the falling rain, is the roof. Therefore, its characteristics strongly influence the subsequent quality of the roof runoff [7]. 
Impermeable roof surfaces represent a pollution sink from where the pollutants are washed off, becoming a part of the runoff. The contaminants depositing on the surface depend on the roof accessibility, location, and weather condition the roof surface is exposed to [15]. Animal excrements from birds, reptiles, and small mammals, deposited dust, leaves, and pollen, as well as the formation of lichens and mosses are typical external pollution sources [17]. Pathogenic bacteria are primarily found in the faeces of animals, which are either deposited on the roof directly or brought to the roof surface by the wind. The deposited material is dissolved by the incoming rainwater, thereby, degrading the roof runoff quality [18].

Metals, such as copper, zinc, aluminium, and lead, are often used in roofing materials. Copper and zinc are also generally used for gutters and pipes [11]. Corrosion products and dissolved heavy metals due to a low $\mathrm{pH}$-value lead to leaches into the runoff [17]. Further, the installation of metal roofs leads to reduced concentrations of feacal bacteria due to the low emissivity of metal, resulting in higher surface temperatures on the roof. However, the effect of additional sterilization, due to the installation of metal roofs, does not result in clearly superior rainwater quality [19]. Wilber et al. [20] showed that thatched roofs produce runoff of higher turbidity and the highest degree of organic contamination. Lee et al. [15] states that galvanised and clay tiles show the most suitable behaviour as roofing materials for RWH applications.

The material of the roof and the subsequent distribution system have a considerable influence on the rainwater runoff quality. However, Gikas and Tsihrintzis [11] suggest that the spatial conditions of an RWH system location, including surrounding fauna and the accessibility, have a bigger influence on the harvested rainwater quality than the roof construction material itself.

Storage management. Regardless of the purpose of the RWH system, whether it serves as a potable or non-potable source, its main components are the catchment area, the storage, and the treatment unit. In the following subsection the influence of the storage reservoir on the water quality is discussed.

Especially in rural areas, most water reservoirs are made out of clay or concrete. Wilber et al. [20] did not observe any noteworthy differences in the water quality. Nevertheless, concrete tanks were observed to contribute manganese to the water body although their concentrations were below those recommended by international water standards.

Water reservoirs generally should be sealed in order to decrease the risk of additionally external pollution of the storage water. Additionally, water withdrawal should occur via valves at the bottom of the reservoir and not via buckets on the water surface [21]. Further, water quality tends to degrade if not in movement. Therefore, stagnating water bodies, over a long period of time, should be avoided [22]. In order to prevent contamination through heavy sedimentation and built microorganisms, storage tanks should regularly be cleaned and maintained [23].

First-flush effect. The mobilisation of deposited material on the roof is not constant. The amount of dissolved contaminants in the runoff is at its highest during the first few minutes of a rain event. This stronger contaminated runoff is called first-flush. In addition to deposited matter after a longer dry period, weathering and corrosion products of the roof cover and drainage systems can contaminate the runoff [24].

The first-flush can easily be hindered to enter the RWH system. It occurs during the first $2 \mathrm{~mm}$ of rainfall. Hence, during the first minutes of a rain event the first-flush must be diverted into a different collecting vessel [14]. First-flush devices increase the general water quality of the harvested rainwater [18]. Gikas and Tsihrintzis [11], however, observed that the division of the first-flush indeed improves the physicochemical quality 
of the collected rainwater while it does not prevent microbial contamination of the stored water.

General discussion. The main water quality influence factors can be summarised as following [25]:

- Roof material: chemical characteristics, roughness, surface coating;

- Catchment parameter: size, inclination, exposure;

- Precipitation: intensity, wind, duration;

- Local weather: season, preceding dry periods;

- Chemical properties of pollutants.

The degree of accumulated contaminants on the roof surface is lowered by frequent and partially heavy rain events. Coarse substances deposited on the roof surface, such as leaves, should be filtered prior to the subsequent distribution system due to their tendency of degrading the overall water quality. Normal meshes, being cleaned regularly, are simple but effective means of filtration holding back coarse matter. The incorporation of environmental conditions and weather patterns of any given site allows predicting the extent of rainwater contamination, chemical as well as bacterial load wise, during an occurring rain event. Possible external contamination sources are summarised and schematically depicted in Figure 1 [20].

The results of the conducted water tests and the literature search are compared with the World Health Organization (WHO) [26] water quality standard, the German Trinkwasserverordnung (TrinkwV) [27] and the Cambodian drinking water standards [28]. No health related or alarming excess of physicochemical or mineral parameters are observed. All microbial parameters exceed the applied water quality regulations by far. Since most bacteria are known to endure and survive the storage process, some means of treatment must be applied in order to meet drinking water regulations [29].

\section{DEVELOPMENT OF A SOLAR DRIVEN RAINWATER HARVESTING SYSTEM}

The PV driven RWH system model is implemented using Simscape/Simulink, a MATLAB application. Basis of the model is the weather scenario which is generated using MATLAB [5] scripts.

\section{Precipitation generator}

The precipitation generator is implemented following the algorithm developed by Apipattanavis et al. [30] and further developed by Basinger et al. [3]. Their model uses historical data which is used to generate the scenario rain events. The historical data is provided by Kirsch [7]. The data covers 27 consecutive years, from 1981 to 2007. The precipitation is recorded on a daily base. The area in which the ACCB is located is struck by monsoon like rain events, with the rainy season spreading from May to October. From January to March hardly any rain occurs with precipitation heights of less than $20 \mathrm{~mm}$ on average.

The annual precipitation height of the utilized rain data is depicted in Figure 2. The minimum rainfall occurred in 1984 with an annual precipitation height of $367.4 \mathrm{~mm}$. The dry season lasted 9 months while the rainy season lasted 3. However, the year 1984 resembles a major outlier. Excluding the year 1984, the lowest rainfall occurred in the year 1983 with a total annual rainfall of $996 \mathrm{~mm}$. The dry season lasted 8 months while the rainy season lasted 4 . The highest annual rainfall occurred in 1995 with a total rainfall of $1,765.4 \mathrm{~mm}$. The dry season lasted 4 months while the rainy season lasted 8 . The average annual precipitation height according to the data is $1,334.77 \mathrm{~mm}$. The dry season lasts on average 4 to 5 months while the rainy season lasts 8 to 7 months. 


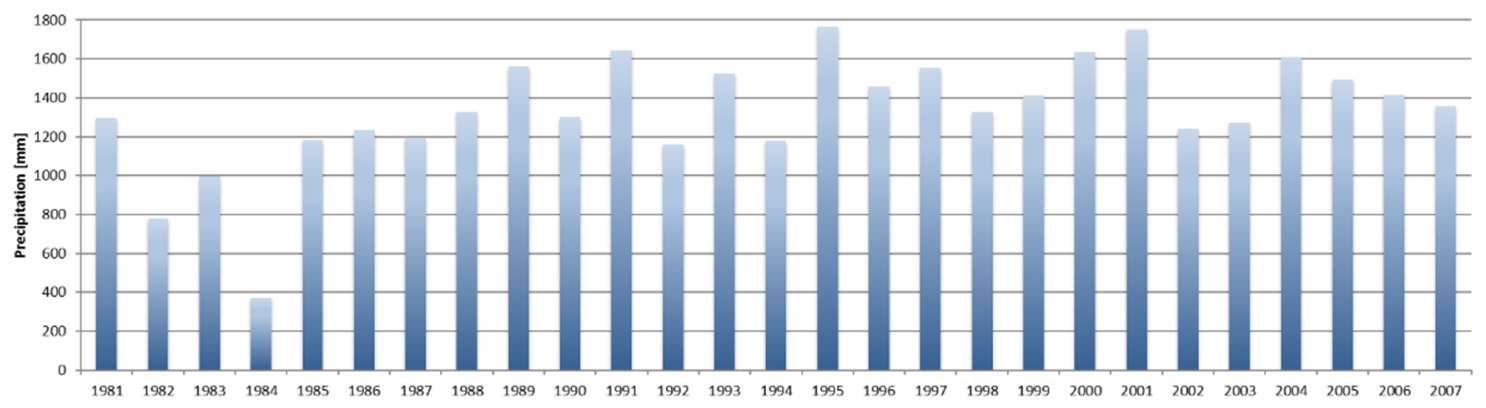

Figure 2. Annual precipitation height of 27 consecutive years in Cambodia

\section{Rainwater harvesting system}

In the following, the essential components of the developed RWH system are discussed and their implementation shown. The simplified RWH scheme is shown in Figure 3. The RWH system, including the energy system, is modelled and simulated using Simscape, a MATLAB Simulink [5] application. Simscape provides an environment for modelling and simulation of physical systems, such as hydraulic and energy systems, by providing fundamental building blocks. It employs, in contrast to Simulink, the Physical Network approach, which is particularly suited for simulating systems that consist of real physical components [31].

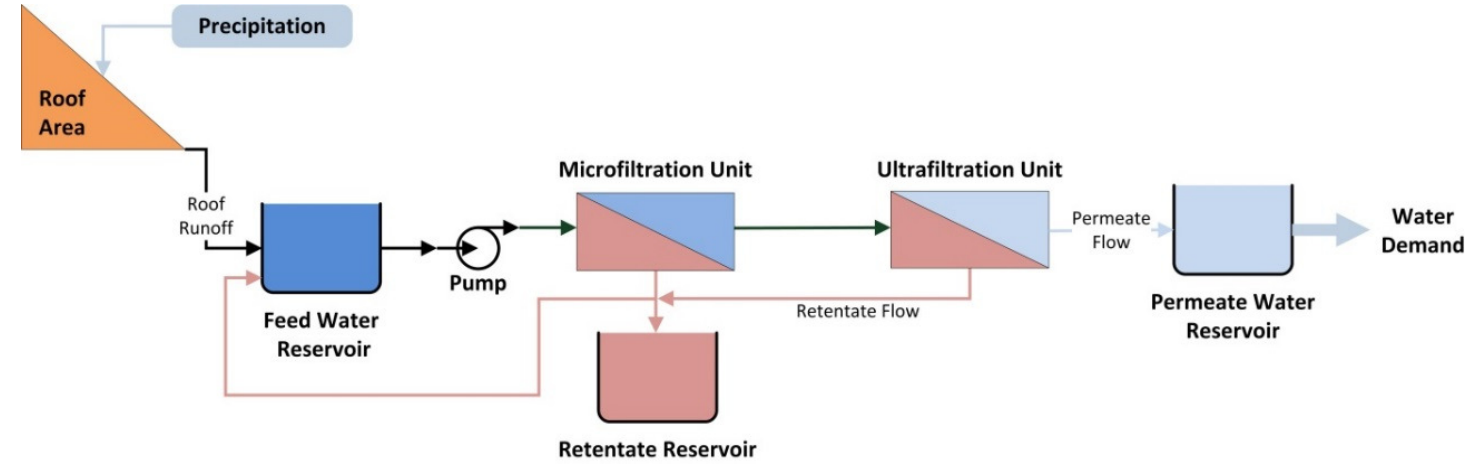

Figure 3. Simplified RWH system scheme without PV modules

Roofs. Rain falling upon the roof is converted into roof runoff. Hence, it represents the initial component in the RWH model. The catchment area in the ACCB is set by the available buildings. Each building is modelled separately. Their characteristics are listed in Table 1. The applied water demand of each building or zone (food preparation area) are also listed in Table 1. Clay tiles are used as the roofing material resulting in a Runoff Coefficient (RC) of 0.84 . The runoff coefficient is a dimensionless parameter that takes losses due to spilling, leakage, catchment surface wetting, and evaporation into account. The water demand of each building was measured and provided by BanTec [9].

Table 1. Building characteristics and their daily water demand per capita

\begin{tabular}{ccccc}
\hline Building & Catchment area $\left[\mathrm{m}^{2}\right]$ & $\mathrm{RC}$ & $\begin{array}{c}\text { Number of } \\
\text { people }\end{array}$ & $\begin{array}{c}\text { Daily water demand } \\
\text { per capita [L/day] }\end{array}$ \\
\hline Volunteer house & 126.120 & 0.84 & 5 & 84.02 \\
Office house & 130.641 & 0.84 & 2 & 61.86 \\
Wooden house & 94.578 & 0.84 & 4 & 95.12 \\
Education centre & 350.00 & 0.84 & 5 & 30.00 \\
Quarantine & 243.680 & 0.84 & 1 & 80.00 \\
Khmer house & 243.680 & 0.84 & 8 & 82.73 \\
Food preparation area & $-/-$ & $-/-$ & $-/-$ & 250 \\
\hline
\end{tabular}


The resulting rainwater runoff is calculated applying eq. (1):

$$
q_{\text {runoff }}=A_{\text {catchment }} \times \mathrm{RC} \times P_{\text {rain }}
$$

Water reservoir. The water reservoir is supposed to be installed below surface so that evaporation losses can be neglected. Additionally, other losses, such as infiltration into storage material, are not considered, either. The reservoir material is concrete. The water balance was formulated amongst others by Lee et al. [32] resulting in eq. (2) and (3) and its derivative, eq. (4):

$$
\begin{gathered}
V_{t+1}=V_{t}+q_{\text {in }}-q_{\text {out }}-E v a_{\mathrm{t}}-L_{t}, \quad V_{t}>0 \\
V_{t+1}=V_{t}+q_{\text {in }}-q_{\text {out }} \\
\frac{d V}{d t}=q_{\text {in }}-q_{\text {out }}
\end{gathered}
$$

Three reservoirs are applied in the RWH system model. First, the cumulative rainwater runoff is collected in the feed reservoir which is located before the treatment. The permeate reservoir is located after the treatment and serves as the fresh water source for the water demand. Its volume is set to $3 \mathrm{~m}^{3}$. In doing so, water quality considerations, such as stagnation, can easily be taken care of. Its size correlates to the site's daily water demand. The retentate reservoir collects the retentate of the treatment process. Depending on the recirculation factor of the retentate, the reservoir tank might be neglected. In the set up at hand the retentate is completely recirculated to the feed reservoir. Hence, only water from cleaning the treatment facilities are collected here. In addition, the feed reservoir is not dimensionally defined in order to determine its optimal dimension for the RWH system.

Treatment. Membrane filtration methods are widely used for treating contaminated or polluted water. Traditional filtration systems are able to withhold particles bigger than $10 \mu \mathrm{m}$. Membrane filtration systems are able to separate bacteria, viruses, and even ionic elements from the feed water. The pore size of the membrane determines the maximum size of the particles passing through. The different technologies and the matter that they are able to withhold are depicted in Figure 4.

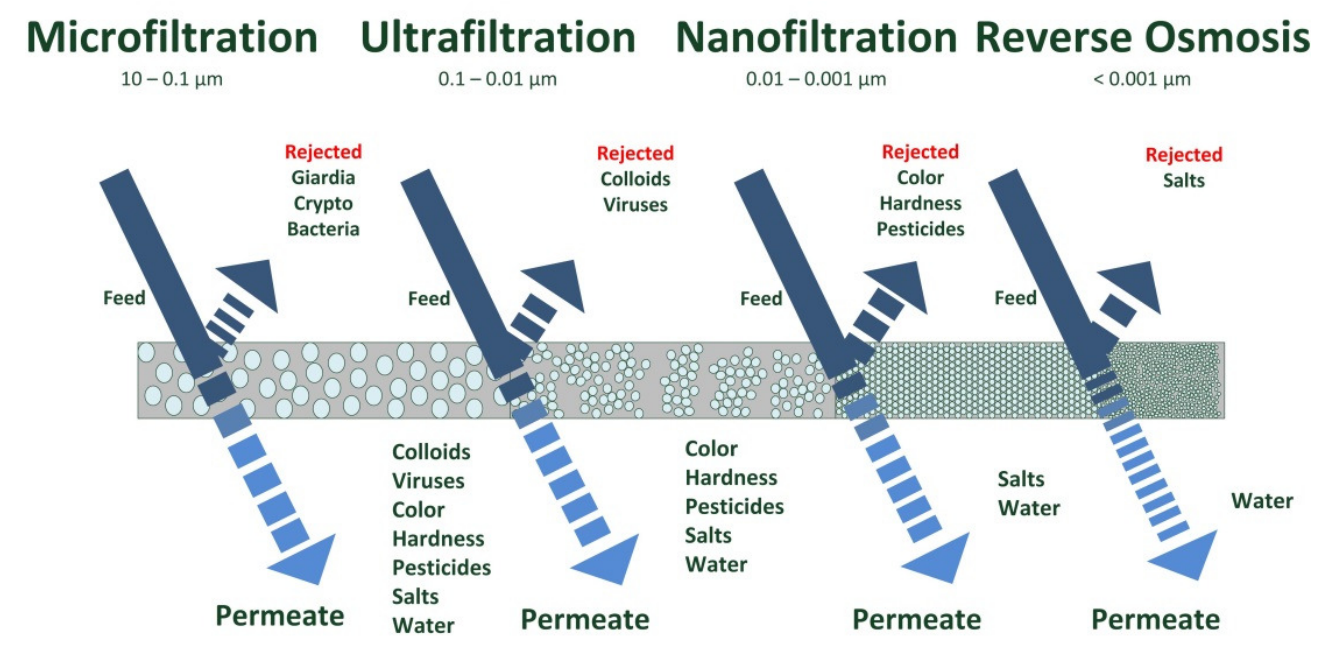

Figure 4. Classification of pressure driven membranes and schematic illustrations of their operation are according to the pore size [29] 
The applied treatment methods are dependent on the rainwater runoff quality. Membrane filtration, whether in combination with subsequent disinfection or as a standalone solution, has been successfully applied for producing drinking water. Disinfection technologies, such as chlorination, ozonation, and UV-irradiation, can become unnecessary when membrane filtration systems are utilised. Hagen [33] examined the microbial removal rate of Microfiltration (MF) and Ultrafiltration (UF) and concluded that a subsequent application of disinfection is needless. In their survey Thomas et al. [34] found out that 30\% of RWH operators in the US use membrane filtration as their only means of treatment for producing potable water. Using membrane technologies as the only means of treatment of RWH systems, is also recommended by others $[2,35,36]$.

As pointed out, physicochemical parameters, anions, and metalloids are not of any concern according to the drinking water guidelines of the WHO [26], Germany [27], and Cambodia [28]. Therefore, treatment focuses on the removal of microbial parameters. The suggested and designed treatment system of the RWH model consists of a MF with a subsequent UF hollow fibre module. The MF unit is installed prior to the UF as more coarse matter withheld during MF could block the UF unit.

MF and UF are operated in crossflow resulting in a low permeate output compared to the retentate output. Therefore, the retentate is recirculated to the feed reservoir as mentioned above.

The driving force of membrane filtration systems is the applied pressure difference, also called Transmembrane Pressure (TMP). The resulting permeate flux depends on the TMP and the resistance induced by the membrane:

$$
\text { Flux }=\frac{\text { Transmembrane pressure }}{\text { Resistance }}
$$

During operation, rejected particles tend to settle down on the membrane surface, which increases the resistance. This leads to a decreasing permeate flow. The settled down particles form a so-called cake layer.

The implementation of the dynamic crossflow filtration of the MF and UF unit follows the equations developed by Song [37]. The implementation is based on the assumption of the development of an equilibrium zone in which the cake layer thickness does not change with time. This equilibrium moves from the beginning of the membrane to the end. Once the entire membrane is in equilibrium state, the permeate flux becomes constant with a constant TMP. This process is schematically depicted in Figure 5.

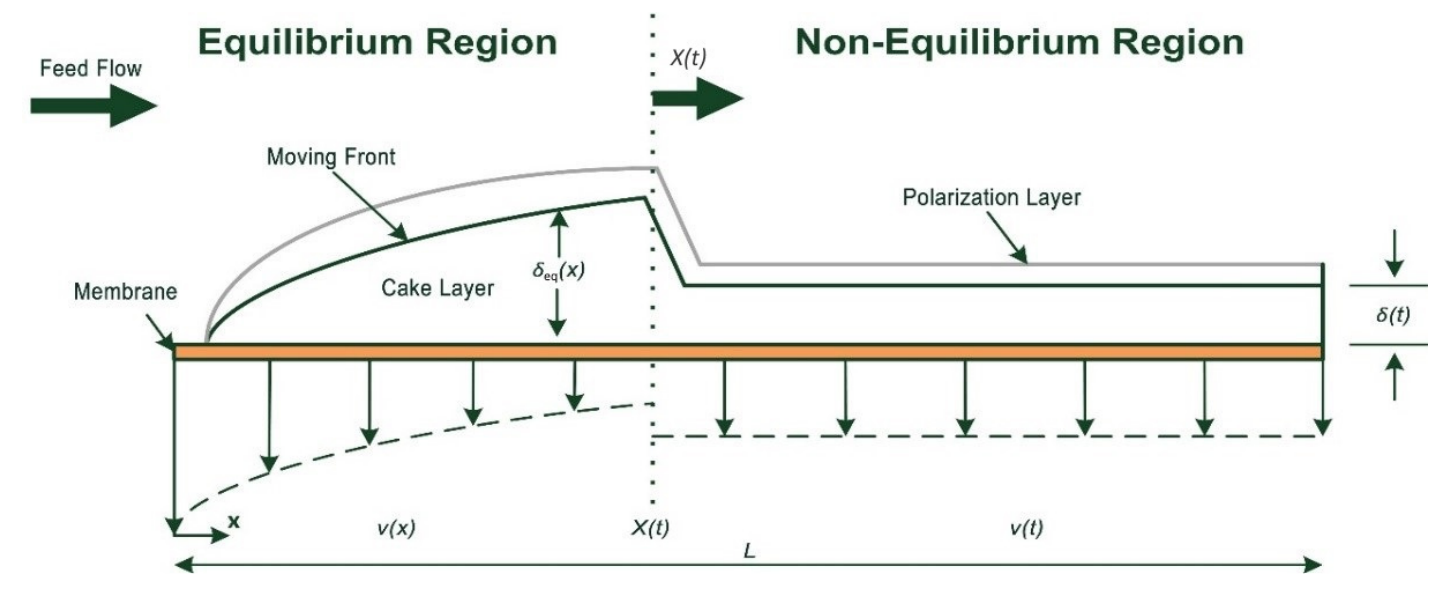

Figure 5. Schematic illustration of a crossflow filtration channel with its equilibrium and non-equilibrium realm adapted from [37], in the former section flux and cake layer thickness are functions of location and in the latter they are functions of time 
The average permeate flux of the treatment unit consists of a time dependent $[v(T)]$ and location dependent $\left[v_{\mathrm{eq}}(x)\right]$ permeate flux term, eq. (6) and (7), respectively, and is calculated according to eq. (8). The calculation of the average permeate flux is dependent on the steady-state time which is the time that the equilibrium needs to reach the end of the membrane. As long as $t<t_{\mathrm{ss}}$, the equilibrium has not reached the end of the membrane. As the equilibrium front moves farther to the end of the membrane, the average flux predominantly becomes affected by the equilibrium region. Once $t_{\mathrm{ss}}$ is reached, the permeate flux becomes constant at each position of the membrane:

$$
\begin{gathered}
v(t)=\frac{\Delta p-\Delta p_{\mathrm{c}}}{R_{\mathrm{bm}}} \times\left(1+\frac{2 r_{\mathrm{c}}\left(\Delta p-\Delta p_{\mathrm{c}}\right)}{R_{\mathrm{bm}}^{2}} \times \frac{c_{\mathrm{o}}}{c_{\mathrm{g}}} \times t\right)^{-\frac{1}{2}} \\
v_{\mathrm{eq}}(x)=\left(\frac{2}{3}\right)^{\frac{1}{3}} \times\left(\frac{D_{\mathrm{dif}}^{2} \gamma}{x}\right)^{\frac{1}{3}} \times\left(\frac{c_{\mathrm{g}}}{c_{0}}-1\right)^{\frac{1}{3}} \\
J(t)=\left\{\begin{array}{c}
\frac{1}{L}\left[\int_{0}^{X(t)} v_{\mathrm{eq}}(x) d x+[L-X(t)] v(t)\right], \quad t<t_{\mathrm{ss}} \\
\left.1.33\left(\frac{D_{\mathrm{dif}}^{2} \gamma}{L}\right)^{\frac{1}{3}}\left(\frac{c_{\mathrm{g}}}{c_{0}}-1\right)\right)^{\frac{1}{3}}, t \geq t_{\mathrm{ss}}
\end{array}\right.
\end{gathered}
$$

$D_{\text {dif }}$ is calculated according to eq. (9). It is dependent on the dynamic viscosity $\mu$ and average particle radius $a_{\mathrm{p}}$. Due to missing data, media related parameters are approximated based on or taken from Song [37]. The particles are assumed to be spherical. The utilised feed parameters are listed in Table 2:

$$
D_{\text {dif }}=\frac{k_{\mathrm{B}} T}{6 \pi \mu a_{\mathrm{p}}}
$$

Table 2. Applied feed parameters and shear rate at the membrane surface

\begin{tabular}{ccc}
\hline Parameter & MF & UF \\
\hline$a_{\mathrm{p}}[\mu \mathrm{m}]$ & 0.1 & 0.01 \\
$M[\mathrm{~Pa} \mathrm{~s}]$ & $8.93 \times 10^{-4}$ & $8.93 \times 10^{-4}$ \\
$T[\mathrm{~K}]$ & 293.15 & 293.15 \\
$c_{\mathrm{o}}$ & 0.001 & 0.001 \\
$c_{\mathrm{g}}$ & 0.6 & 0.6 \\
$R_{\mathrm{bm}}[(\mathrm{Pa} \mathrm{s}) / \mathrm{m}]$ & $1 \times 10^{9}$ & $4.02 \times 10^{8}$ \\
$\gamma[\mathrm{L} / \mathrm{s}]$ & $1 \times 10^{3}$ & $1 \times 10^{3}$ \\
\hline
\end{tabular}

Control. The RWH model is controlled based on the volume of the permeate reservoir. Once the maximum volume is reached, the treatment unit pauses. During the treatment stop, fresh water is constantly withdrawn from the permeate reservoir based on the water demand of the individual buildings. When the treatment process halts, it needs to be backwashed to avoid degradation of the membrane surface due to fouling processes. The backwash is considered in the simulation by setting the treatment parameters, location of equilibrium, time-dependent permeate flux, and overall permeate flux to its initial values. The treatment starts again when the permeate reservoir volume reaches its minimum. Table 3 summarises the important control parameters which also include the pump, inducing the driving force of the whole RWHS system model. The permeate 
reservoir minimum of $1.5 \mathrm{~m}^{3}$ is chosen in order to account for a safety residual volume if the minimum is undercut.

Table 3. Control parameters of RWH system model

\begin{tabular}{cc}
\hline Parameter & Value \\
\hline TMP [bar] & 0.5 \\
Maximum volume in permeate reservoir $\left[\mathrm{m}^{3}\right]$ & 3 \\
Minimum volume in permeate reservoir $\left[\mathrm{m}^{3}\right]$ & 1.5 \\
Pump efficiency & 0.9 \\
\hline
\end{tabular}

General setup. The simulation time period is one year. A conduit system, including pipes and other orifices, is not considered since the focus of the simulation lies in modelling and examining the long term behaviour of the RWH system and evaluating its potential.

\section{Solar radiation}

The solar power examination is an estimate of the ability of the currently installed PV system to run the designed RWH system. The potential is determined based on an energy storage balance observation.

The solar radiation generation is based on the precipitation generator. It is generated based on the average annual irradiation and the average monthly duration of sunshine. The data set length is the same as the length of the generated precipitation time series.

The utilized PV panel at the ACCB is a ReneSolarVirtus II polycrystalline $250 \mathrm{~W}_{\mathrm{p}}$ module. In total 40 panels, $10 \mathrm{~kW}_{\mathrm{p}}$, are installed. The characteristics of one PV module are listed in Table 4. The PV output power is determined following eq. (10) and the PV efficiency is calculated by eq. (11):

$$
\begin{gathered}
P_{\text {solar }}=P_{\text {irr }} \times A_{\text {mod }} \times n_{\mathrm{PV}} \times \eta_{\mathrm{PV}} \times \mathrm{PR} \\
\eta_{\mathrm{PV}}=\frac{P_{\mathrm{PV}}}{A_{\mathrm{mod}} \times P_{\mathrm{irr}}}
\end{gathered}
$$

Table 4. Characteristics of installed PV system

\begin{tabular}{ccccc}
\hline $\begin{array}{c}\text { PV module } \\
\text { surface area }\left[\mathrm{m}^{2}\right]\end{array}$ & $\begin{array}{c}\text { Peak power } \\
\text { per module }\left[\mathrm{W}_{\mathrm{p}}\right]\end{array}$ & $\begin{array}{c}\text { Efficiency } \\
\text { coefficient [\%] }\end{array}$ & $\begin{array}{c}\text { Performance } \\
\text { ratio }\end{array}$ & $\begin{array}{c}\text { Installed } \\
\text { modules }\end{array}$ \\
\hline 1.63 & 250 & 15.37 & 0.84 & 40 \\
\hline
\end{tabular}

The energy storage is not designed in detail. However, a common battery system, being either a lead-acid or lithium-ion system, is assumed to be the appropriate system at hand. Both battery systems are the most common ones and are widely in use, both in industrialized and rural areas, as they are easy to set up and to maintain during the use. Losses during the storage process are regarded for with a storage efficiency factor of $80 \%$ which represents standard battery system loss-coefficients. The storage is provided with solar energy from the PV modules and provides the RWH system pump power demand.

\section{RESULTS AND DISCUSSION}

The aim of the investigation is to model the behaviour of a PV driven RWH system, by means of historic weather data and existing site data from the case study location, over the simulation period as well as the dynamic of the developed model. 


\section{Rainwater harvesting system behaviour}

The start of the simulation scenario is set to June. RWH systems should be installed and initially operated shortly before the main rain seasons. By doing so, excess rainwater can be stored from the beginning of operation for dry periods.

Precipitation generator. The introduced algorithm for the precipitation generator was successfully implemented. The average monthly precipitation of the scenario year is depicted in Figure 6. The annual precipitation amount is $1,329.7 \mathrm{~mm}$ which is slightly below the average annual precipitation amount of the historic data $(1,334.77 \mathrm{~mm})$. The dry season lasts 4 months while the rainy season lasts 8 months which correlates with the respective average months. Hence, the basis for the subsequent simulation of the RWH system model is laid.

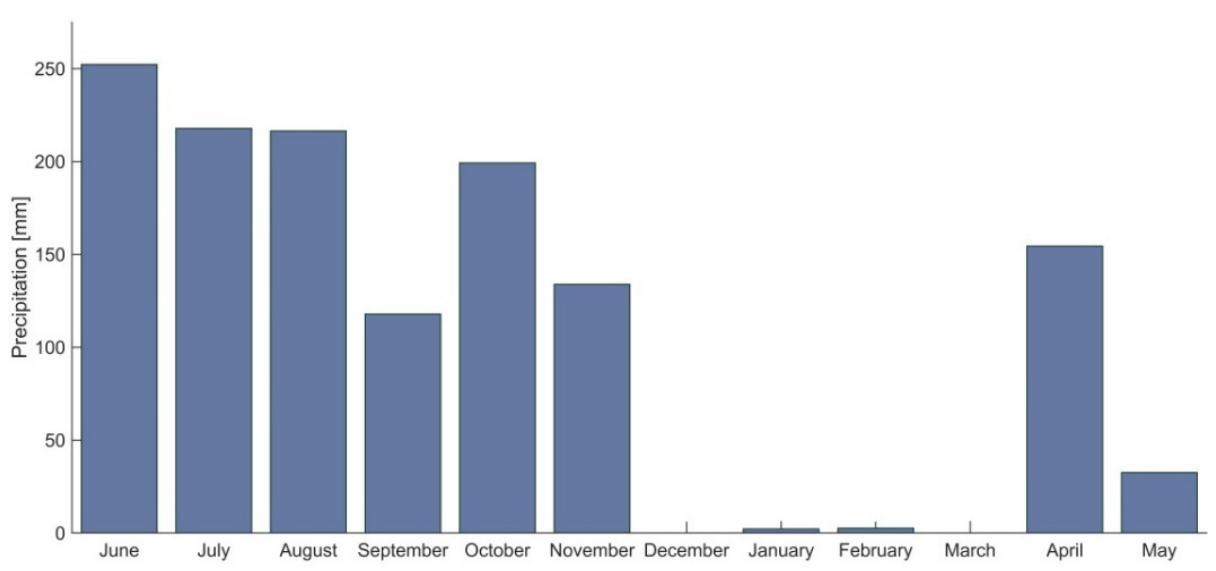

Figure 6. Average monthly precipitation height of simulated reference year

Rainwater harvesting system behaviour. The annual water demand is $754.14 \mathrm{~m}^{3}$ and the cumulative runoff over the scenario period is $1,329.7 \mathrm{~m}^{3}$. The permeate volume produced over one year is $754.41 \mathrm{~m}^{3}$.

The feed reservoir volume development is depicted in Figure 7. It can be seen that it accumulated vast water amounts during the rainy season. During the dry season, however, $328.7 \mathrm{~m}^{3}$ are withdrawn which needs to be covered by the accumulated runoff during the rainy season. Therefore, the volume of the reservoir must at least meet the withdrawn amount. Besides that, it can also be seen that at the end of the year over $500 \mathrm{~m}^{3}$ of water are still in the reservoir right before the upcoming rainy season.

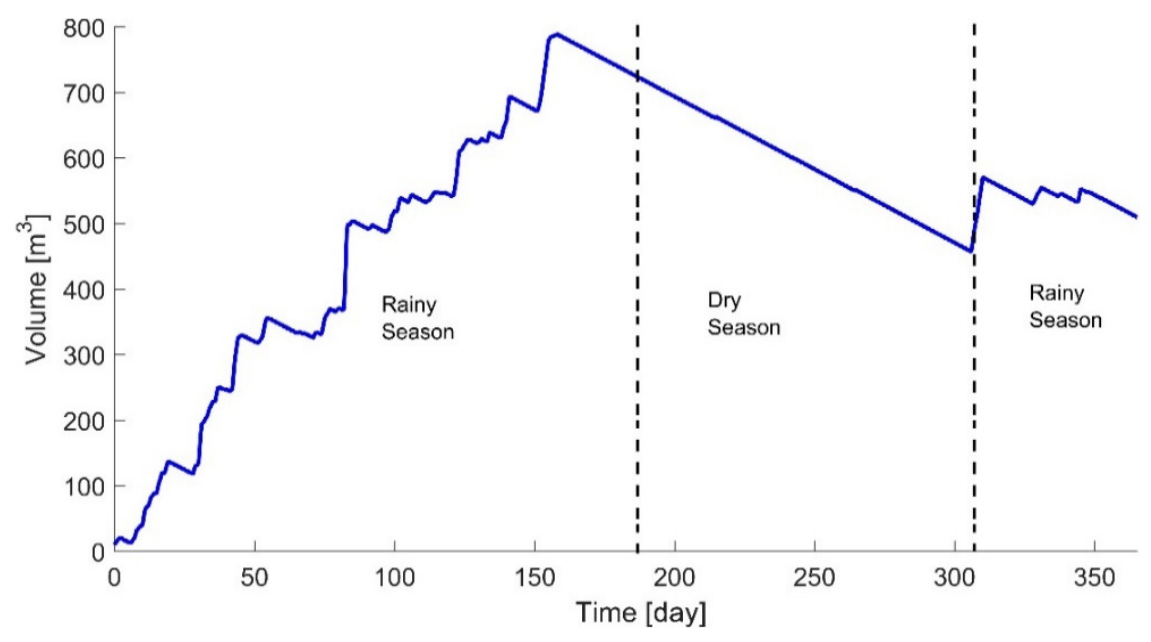

Figure 7. Feed reservoir volume development over simulation period 
In Figure 8, the water balance of the feed reservoir as well as the input and output flows, being the rainwater runoff, treatment feed, and recirculated retentate, are exemplarily depicted for June. It can be seen that most of the input is accounted for by the recirculated retentate while the rainwater runoff reflects only a small portion. Further, the dynamic of the feed reservoir is visible. Feed withdrawal and recirculated retentate follow the same dynamic which is based on the volume level of the permeate reservoir.

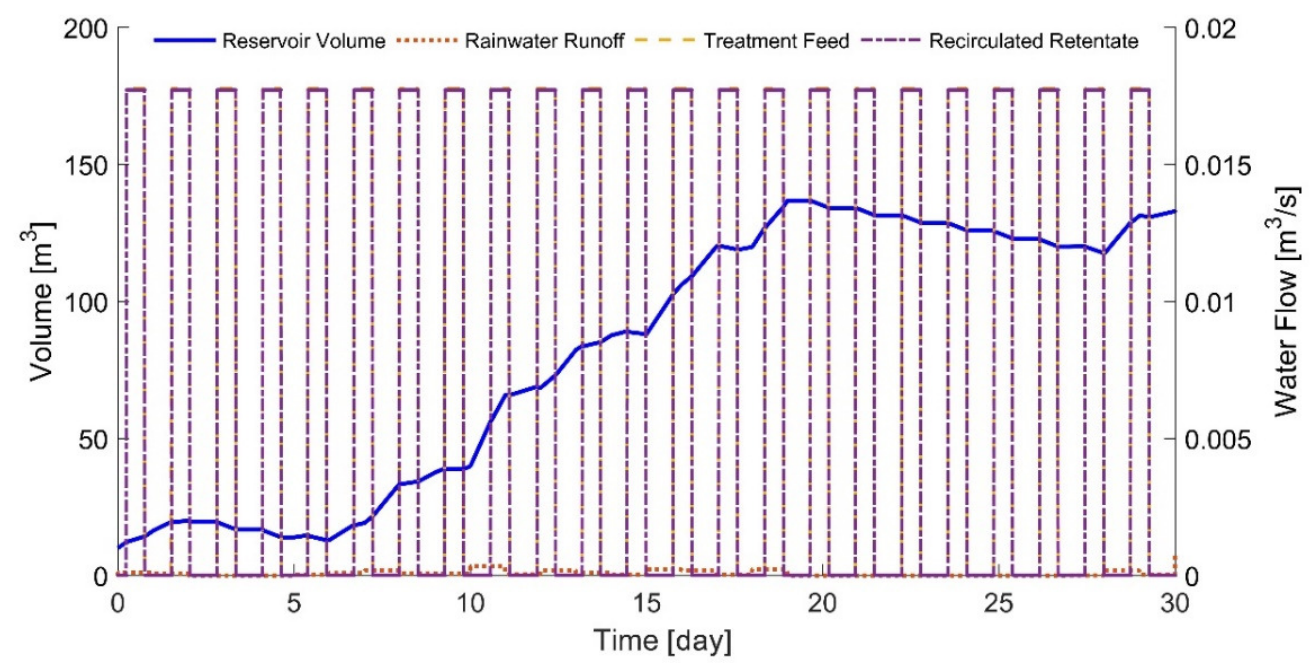

Figure 8. Feed reservoir water balance and input, rainwater runoff and recirculated retentate, and output, treatment feed, water flows of the reservoir in June

The RWH system is controlled by the volume of the permeate reservoir. The maximum set volume is $3 \mathrm{~m}^{3}$ and the minimal set volume is $1.5 \mathrm{~m}^{3}$, as visible in Figure 9. It can be seen that the permeate cycle lies between 1 to 2 days. The permeate flow, and thus the treatment units, behaves in accordance to the provided dynamic. Once the reservoir reaches its upper boundary, the permeate production ceases and hence the treatment system pauses. The water demand, on the other hand, is constantly met and withdrawn from the permeate reservoir. The amount of produced permeate depends on the dimension and operation of the treatment system. Therefore, changes in the treatment system will lead to different permeate outputs with which a changing demand can be met without difficulty.

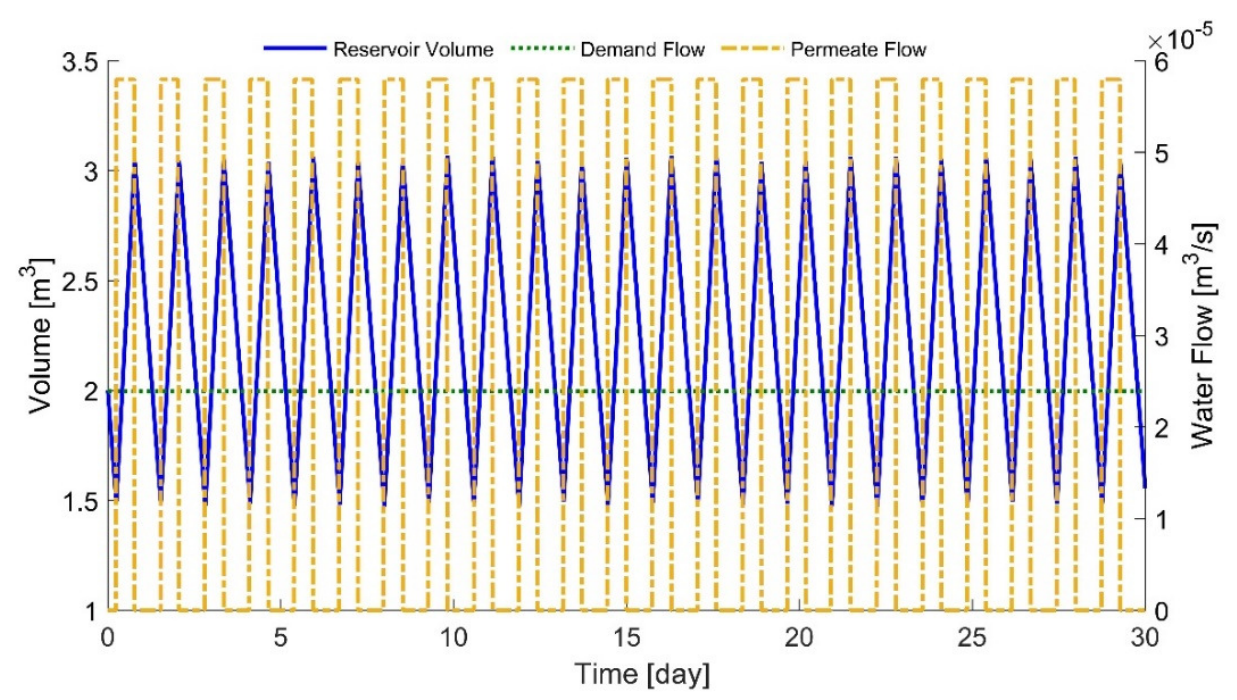

Figure 9. Permeate reservoir water balance and the input, permeate, and output, demand, water flows in June 
The ratio of produced permeate per feed is called Recovery Ratio (RR). It is determined following eq. (12):

$$
\text { Recovery ratio }=\frac{\text { Permeate flow }}{\text { Feed flow }} \times 100 \%=\frac{\text { Permeate volume }}{\text { Feed volume }} \times 100 \%
$$

RR of the system at hand is $0.33 \%$. This means, that only a small fraction of feed is converted into permeate while most of the feed is flushed away as unused retentate. The RR is very small and holds a huge optimization potential. Adjusted treatment dimensions and parameters as well as an intelligent pump control mechanism could lead to an increase of the RR. The recirculation of the retentate to the feed reservoir allows the unused feed water to be treated again. As the amount of produced permeate is considerably low, the retentate is only fractionally more polluted respectively contaminated bearing no additional concerns regarding the water quality.

The main RWH system parameters are summarised in Table 5.

Table 5. Summary of main RWH system model parameters

\begin{tabular}{cc}
\hline Parameter & Value \\
\hline Annual water demand $\left[\mathrm{m}^{3}\right]$ & 754.14 \\
Annual rainwater runoff $\left[\mathrm{m}^{3}\right]$ & $1,329.70$ \\
Annual permeate production $\left[\mathrm{m}^{3}\right]$ & 754.41 \\
Daily water demand $\left[\mathrm{m}^{3} / \mathrm{day}\right]$ & 2.06 \\
Feed withdrawal rate $\left[\mathrm{m}^{3} / \mathrm{s}\right]$ & 0.018 \\
Treatment system recovery $[\%]$ & 0.33 \\
\hline
\end{tabular}

The results are applicable for the entire historic rain data. The minimum outlier can be compensated for beforehand by high precipitation years, depending on the size of the feed water reservoir. Excluding the minimum outlier results in $100 \%$ adaptability the RWH system.

\section{Energy consumption}

The annual pump energy demand is $3,511.6 \mathrm{kWh}$ while the annually generated solar energy is 4,529.3 $\mathrm{kWh}$. In Figure 10 the energy content of the energy storage is depicted. It is visible that the development of the storage energy curve shows an opposing trend compared to the feed reservoir development. During rainy season, the solar input is comparatively low. During dry season, on the other hand, the solar input is considerable. However, only during a small period of the rainy season, the energy storage level drops below zero. The available energy at the end of the simulation scenario is significant. Hence, the potential of running the RWH system with the available installed PV is given.

The main parameters of the energetic examination are summarised in Table 6 .

For running the RWH system alone, the authors expect that a battery system with an energy content of $150 \mathrm{kWh}$ is able to provide the RWH system with sufficient energy. The battery size is estimated by integrating the power demand of the RWH system. As mentioned above and visible from the energy content development of the energy storage unit in Figure 10, the generated energy from the installed PV modules can be further utilized for supplying the rest of the site with energy. The consumers mostly consist of lights, fans, and technical equipment. Hence, the authors believe that a battery system with an energy content of $200 \mathrm{kWh}$ to be adequate for providing the ACCB with energy. The resulting battery storage demand is reasonable for both the battery size and for the resulting investment. 
The utilization of PV in combination with an energy storage (battery) system is applicable for all historic weather events. Even in the year with the highest amount of precipitation (1995), the dry season lasts 4 months. During the rainy season the irradiation does not cease to exist. Therefore, the suggested battery size is assumed to be sufficient.

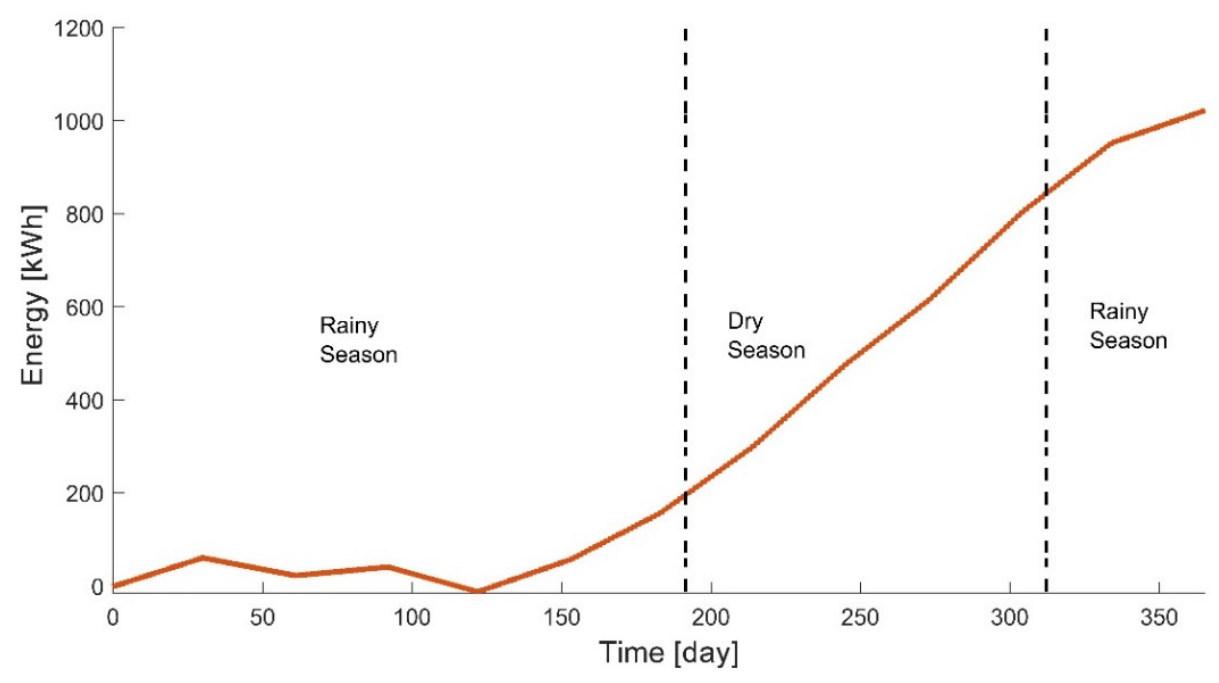

Figure 10. Energy content of energy storage unit

Table 6. Summary of energy related parameters of RWH system model

\begin{tabular}{cc}
\hline Parameter & Value \\
\hline Annual energy demand [kWh] & $3,511.60$ \\
Annual solar energy input [kWh] & $4,529.30$ \\
Power demand pump [W] & 987.37 \\
Energy storage efficiency [\%] & 80.00 \\
\hline
\end{tabular}

\section{SUMMARIZING ANALYSIS}

Impermeable roof surfaces proved themselves to produce rainwater runoff of generally good quality. Despite the fact that depending on the roof material different runoff amounts and qualities are achieved, the most common roof types, such as metal, clay, and asphalt shingle, generate runoff of similar quality. However, ambient conditions, such as accessibility and nearby vegetation, strongly influence the quality of the runoff. It can be said that by decreasing depositions, such as leaves and faeces, on the roof, the runoff quality increases. Roof harvested rainwater is easily collected by installing gutters, downpipes, a conduit system, and a water storage system. First-flush devices represent a safe means of avoiding the highly contaminated first-flush. Such devices mainly increase the runoff quality on a physicochemical base while microbiological contamination is hardly affected by them. Since physicochemical parameters in the water turned out to be not critical, the installation of a first-flush device is not considered as necessary. The water tanks should be protected from external contamination and thus be sealed. The withdrawal of water should be carried out using valves instead of buckets in order to minimise the external pollution and contamination sources. The amount of physicochemical and chemical pollutants generally meets water quality standards while the amount of microbiological pollutants, such as bacteria and viruses, exceeds water quality guidelines. Therefore, treatment systems for the removal of the microbiological pollutants are inevitable to provide potable water. 
The generation of weather events is based on historical data. Daily rain events are generated by implementing the presented semi-parametric algorithm in MATLAB. The simulated precipitation is based on actual historical data of the case study area. The solar radiation dataset is based on monthly irradiation sequences and the average annual solar radiation.

The results show that the developed rainwater harvesting system is able to provide the ACCB with drinking water generated from rainwater. A minimally required feed reservoir size is estimated based on the largest water volume drop during the dry season. From the water volume development of the reservoir it can also be concluded that provision of water is guaranteed on a long term basis. The highest fraction of water input comes from the recirculated retentate. Due to the significantly low recovery of the treatment system, the recirculation is inevitable. Further, the initial operation date of rainwater harvesting systems can be derived from the feed reservoir volume development. RWH systems should be started shortly before rainy seasons as the water provision during the dry season relies on the accumulated water.

The permeate reservoir volume is, in contrast to the feed reservoir, designed to provide the daily water demand by a factor of 1.5 . Further, it is used for controlling the rainwater harvesting system model. Model control is based on the volume level in the reservoir. The lower volume boundary is chosen in such a way that a backup water volume is accounted for. Advantage of the one to two days renewal of the reservoir content is that stagnation of the water body is avoided. This improves the water quality of the treated water which otherwise would decline.

Although accounted for in the RWH system, a retentate reservoir is not necessary if the recirculation rate is set to $100 \%$. Wastewater resulting from backwash and maintenance processes may necessitate the implementation of a retentate reservoir, depending on the site location.

In addition to the provision of clean water, the potential of running the rainwater harvesting system with a PV plant is investigated. The analysis shows that the currently installed PV power at the ACCB is sufficient to run the RWH system. The available excess energy even allows the provision of energy to the rest of the site. Contrary to the initial operation date of the rainwater harvesting system, the PV system should be initially operated shortly before the dry season.

\section{CONCLUSION}

In this paper, a photovoltaic driven rainwater harvesting system model for the provision of potable water over a period of one year is presented. The model is based on a two-stage, first order non-parametric precipitation generator. Further, the treatment of the rainwater is accounted for as well as the system's control mechanism. In its design and implementation, the model is portable since the stochastic weather generator algorithm is run by historical records and as the model can easily be modified and adapted to different requirements. The model helps to estimate the potential of both, rainwater harvesting as well as using photovoltaic panels as an energy source. For the design of the treatment unit, a thorough literature review regarding the rainwater quality and the sources of the factors, influencing the rainwater quality negatively, is conducted. Since the rainwater harvesting model uses a buffer reservoir (feed reservoir) the optimal size of the buffer reservoir can be evaluated in addition. The same applies for the energy storage unit. A regular battery system, either lead-acid or lithium-ion based, is designated as the energy storage system type. From the simulation results, the size of the energy storage unit is derived and recommended. The model is used for simulating a one year scenario at the Angkor Centre for Conservation of Biodiversity in Cambodia. Although proven powerful, the reliability of the model needs to be proven by a long term test on site. The model is implemented using Simscape/Simulink a MATLAB application. 


\section{ACKNOWLEDGEMENT}

We would like to thank the Angkor Centre for Conservation of Biodiversity and Allwetter Zoo Münster for the possibility to conduct the experiments on site and use the Angkor Centre for Conservation of Biodiversity for the case study.

\section{NOMENCLATURE}

$A_{\text {catchment }}$
$A_{\text {mod }}$
$a_{\mathrm{p}}$
$c_{0}$
$c_{\mathrm{g}}$
$D_{\text {dif }}$
$E v a_{\mathrm{t}}$
$J(t)$
$k_{\mathrm{B}}$
$L$
$L_{\mathrm{t}}$
$n_{\mathrm{PV}}$
$P_{\text {irr }}$
$P_{\mathrm{PV}}$
$P_{\text {solar }}$
$P_{\text {rain }}$
$q_{\text {in }}$
$q_{\text {out }}$
$q_{\text {runoff }}$
$r_{\mathrm{c}}$
$R_{\mathrm{bm}}$
$t$
$t_{\mathrm{ss}}$
$T$
$v(t)$
$v_{\text {eq }}(x)$
$V_{\mathrm{t}}$
$V_{\mathrm{t}+1}$
$X(t)$

roof catchment area

PV module surface area

average particle radius

particle concentration in bulk layer

particle concentration in cake layer

particle diffusion coefficient

evaporation at time $t$

average permeate flux

Boltzmann constant

length of membrane

general losses at time $t$

amount of installed modules

solar radiation

PV peak power

PV power output

daily precipitation

inflow at time $t$

outflow at time $t$

accumulated roof runoff

specific cake resistance

resistance of blocked membrane

time

steady-state time

temperature

time dependent permeate flux

location dependent permeate flux

storage volume at time $t$

storage volume at time $t+1$

position of moving equilibrium

$\left[\mathrm{m}^{2}\right]$
$\left[\mathrm{m}^{2}\right]$
$[\mathrm{m}]$
$[-]$
$[-]$
$\left[\mathrm{m}^{2} / \mathrm{s}\right]$
$\left[\mathrm{m}^{3}\right]$
$[\mathrm{m} / \mathrm{s}]$
$[\mathrm{J} / \mathrm{K}]$
$[\mathrm{m}]$
$\left[\mathrm{m}^{3}\right]$
$[-]$
$\left[\mathrm{W} / \mathrm{m}^{2}\right]$
$[\mathrm{kW}]$
$[\mathrm{W}]$
$\left[\mathrm{L} /\left(\mathrm{m}^{2} \mathrm{day}\right)\right]$
$\left[\mathrm{m}^{3}\right]$
$\left[\mathrm{m}^{3}\right]$
$[\mathrm{L} / \mathrm{day}]$
$\left[(\mathrm{Pa} \mathrm{s}) /\left(\mathrm{m}^{2} \mathrm{~s}\right)\right]$
$[(\mathrm{Pa} \mathrm{s}) / \mathrm{m}]$
$[\mathrm{s}]$
$[\mathrm{s}]$
$[\mathrm{K}]$
$[\mathrm{m} / \mathrm{s}]$
$[\mathrm{m} / \mathrm{s}]$
$\left[\mathrm{m}^{3}\right]$
$[\mathrm{m} 3$
$[\mathrm{m}]$

$[-]$

$[\mathrm{Pa} \mathrm{s}]$

$[\mathrm{L} / \mathrm{s}]$

$[\mathrm{Pa}]$

$[\mathrm{Pa}]$

\section{Abbreviations}

$\begin{array}{ll}\text { PR } & \text { Performance Ratio } \\ \text { RC } & \text { Runoff Coefficient }\end{array}$

\section{REFERENCES}

1. Directive 2000/60/EC of the European Parliament and of the Council of 23 October 2000, Establishing a Framework for Community Action in the Field of Water Policy, OJ L 327, 2000. 
2. Lee, S. and Kim, R., Rainwater Harvesting, Encyclopaedia of Sustainability Science and Technology, pp 8688-8702, Springer New York, New York, USA, 2012.

3. Basinger, M., Montalto, F. and Lall, U., A Rainwater harvesting System Reliability Model based on Nonparametric Stochastic Rainfall Generator, Journal of Hydrology, Vol. 392, No. 3-4, pp 105-118, 2010, https://doi.org/10.1016/j.jhydrol.2010.07.039

4. de Kwaadsteniet, M., Dobrowsky, P. H., van Deventer, A., Khran, W. and Cloete, T. E., Domestic Rainwater harvesting: Microbial and Chemical Water Quality and Point-of-use Treatment Systems, Water, Air \& Soil Pollution, Vol. 224, No. 7, 2013, https://doi.org/10.1007/s11270-013-1629-7

5. REFERENCESMATLAB, Version 8.6.0.267246 (R2015b), The MathWorks In., Natick, Massachusetts, USA, 2015.

6. Angkor Centre for Conservation of Biodiversity, http://www.accb-cambodia.org/de/ index.php, [Accessed: 20-May-2016]

7. Kirsch, H., Wastewater Inventory Siem Reap, Cambodia: A Combination of Social and Natural Science Methods, Pacific News, Vol. 34, No. 6, 2010.

8. Solar GIS, http://solargis.info/doc/_pics/freemaps/1000px/ghi/SolarGIS-Solar-mapSouth-And-South-East-Asia-en.png, [Accessed: 20-May-2016]

9. BAnTec GmbH, Badenallee 1, 14052 Berlin, Germany.

10. Evans, C. A., Coombese, P. J. and Dunstan, R. H., Wind, Rain and Bacteria: The Effect of Weather on the Microbial Composition of Roof-harvested Rainwater, Water Research, Vol. 40, No. 1, pp 37-44, 2006, https://doi.org/10.1016/j.watres.2005.10.034

11. Gikas, G. D. and Tsihrintzis, V. A., Assessment of Water Quality of First-flush Roof Runoff and Harvested Rainwater, Journal of Hydrology, Vol. 466-467, pp 115-126, 2012, https://doi.org/10.1016/j.jhydrol.2012.08.020

12. Montoya-Mayor, R., Fernández-Espinosa, A. J., Seijo-Delgado, I. and Ternero-Rodríguez, M., Determination of Soluble Ultra-trace Metals and Metalloids in Rainwater and Atmospheric Deposition Fluxes: A 2-year Survey and assessment, Chemosphere, Vol. 92, No. 8, pp 882-891, 2013, https://doi.org/10.1016/j.chemosphere.2013.02.044

13. Tsakovski, S., Tobiszewski, M., Simeonov, V., Polkowska, A. and Namieśnik, J., Chemical Composition of Water from Roofs in Gdansk, Poland, Environmental Pollution, Vol. 158, No. 1, pp 84-91, 2010, https://doi.org/10.1016/j.envpol.2009.07.037

14. Bielmyer, G., Arnold, W. R., Tomasso, J. R., Isely, J. J. and Klaine, S. J., Effects of Roof and Rainwater Characteristics on Copper Concentrations in Roof Runoff, Environmental Monitoring and Assessment, Vol. 184, No. 5, pp 2797-2804, 2012, https://doi.org/10.1007/s10661-011-2152-1

15. Lee, J. Y., Bak, G. and Han, M., Quality of Roof-harvested Rainwater - Comparison of different Roofing Materials, Environmental Pollution, Vol. 162, pp 422-429, 2012, https://doi.org/10.1016/j.envpol.2011.12.005

16. Verhoeven, W., Herrmann, R., Eiden, R. and Klemm, O., A Comparison of the Chemical Composition of Fog and Rainwater collected in the Fichtelgebirge, Federal Republic of Germany, and from the South Island of New Zealand, Theoretical and Applied Climatology, Vol. 38, No. 4, pp 210-221, 1987, https://doi.org/10.1007/BF00867414

17. Ahmed, W., Huygens, F., Goonetilleke, A. and Gardner, T., Real-time pcr Detection of Pathogenic Microorganisms in Roof-harvested Rainwater in Southeast Queensland, Australia, Applied and Environmental Microbiology, Vol. 74, No. 17, pp 5490-5496, 2008, https://doi.org/10.1128/AEM.00331-08

18. Göbel, P., Dierkes, C. and Coldewey, W. G., Storm Water Runoff Concentration Matrix for Urban Areas, Journal of Contaminant Hydrology, Vol. 91, No. 1-2, pp 26-42, 2007, https://doi.org/10.1016/j.jconhyd.2006.08.008 
19. Mendez, C. B., Klenzendorf, J. B., Afshar, B. R., Simmons, M. T., Barrett, M. E., Kinney, K. A. and Kirisits, M. J., The Effect of Roofing Material on the Quality of harvested Rainwater, Water Research, Vol. 45, No. 5, pp 2049-2059, 2011, https://doi.org/10.1016/j.watres.2010.12.015

20. Wilbers, G.-J., Sebesvari, Z., Rechenburg, A. and Renaud, F. G., Effects of Local and Spatial Conditions on the Quality of harvested Rainwater in the Mekong Delta, Vietnam, Environmental Pollution, Vol. 182, pp 225-232, 2013, https://doi.org/10.1016/j.envpol.2013.07.019

21. Boelee, E., Yohannes, M., Poda, J.-N., McCartney, M., Cechi, P., Kibret, S., Hagos, F. and Laamrani, H., Options for Water Storage and Rainwater harvesting to improve Health and Resilience against Climate change in Africa, Regional Environmental Change, Vol. 13, No. 3, pp 509-519, 2013, https://doi.org/10.1007/s10113-012-0287-4

22. Pinfold, J. V., Horan, N. J., Wirojanagud, W. and Mara, D., The Bacteriological Quality of Rainjar Water in Rural Northeast Thailand, Water Research, Vol. 27, No. 2, pp 297-302, 1993, https://doi.org/10.1016/0043-1354(93)90089-Z

23. Morrow, A. C., Dunstan, R. H. and Coombes, P. J., Elemental Composition at different Points of the Rainwater harvesting System, Science of the Total Environment, Vol. 408, No. 20, pp 4542-4548, 2010, https://doi.org/10.1016/j.scitotenv.2010.07.002

24. Zobrist, J., Müller, S. R., Ammann, A., Bucheli, T. D., Mottier, V., Ochs, M., Schoenenberger, R., Eugster, J. and Boller, M., Quality of Roof Runoff for Groundwater infiltration, Water Research, Vol. 34, No. 5, pp 1455-1462, 2000, https://doi.org/10.1016/S0043-1354(99)00290-0

25. Lye, D. J., Rooftop Runoff as a Source of Contamination: A Review, Science of The Total Environment, Vol. 407, No. 21, pp 5429-5434, 2009, https://doi.org/10.1016/j.scitotenv.2009.07.011

26. World Health Organization, Guidelines for Drinking-Water Quality, WHO Library Cataloguing-in-Publication Data ( $4^{\text {th }}$ ed.), 2011.

27. Drinking Water Ordinance as amended by the Notice of 2. August 2013 (BGBI. I S. 2977) amended by Article 4 (22) of the Act of 7. August 2013 (BGBI. I S. 3154) (in German).

28. Drinking Water Quality Standards, Kingdom of Cambodia, 2004.

29. Czarny, J., Sattelmayer, T., Spinnler, M. and Präbst, A., Development and Simulation of Rainwater Harvesting Systems in Developing Countries, Term Paper, Technical University of Munich, Munich, Germany, 2015.

30. Apipattanavis, S., Podestá, G., Rajagopalan, B. and Katz, R. W., A Semiparametric Multivariate and Multisite Weather generator, Water Resources Research, Vol. 43, No. 11, 2007, https://doi.org/10.1029/2006WR005714

31. MathWorks, Simscape User's Guide, Vol. R2015a, The MathWorks Inc., 2015.

32. Lee, S. C., Lin, H. T. and Yang, T. Y., Artificial Neural Network analysis for Reliability Prediction of Regional Runoff Utilization, Environmental Monitoring and Assessment, Vol. 161, No. 1-4, pp 315-326, 2010, https://doi.org/10.1007/s10661-009-0748-5

33. Hagen, K., Removal of Particles, Bacteria and Parasites with Ultrafiltration for drinking Water treatment, Desalination, Vol. 119, No. 1-3, pp 85-91, 1998, https://doi.org/10.1016/S0011-9164(98)00117-9

34. Thomas, R. B., Kirisits, M. J., Lye, D. J. and Kinney, J. A., Rainwater harvesting in the United States: A Survey of Common System Practices, Journal of Cleaner Production, Vol. 75, pp 166-173, 2014, https://doi.org/10.1016/j.jclepro.2014.03.073

35. Naddeo, V., Scannapieco, D. and Belgiorno, V., Enhanced drinking Water Supply through harvested Rainwater treatment, Journal of Hydrology, Vol. 498, pp 287-291, 2013, https://doi.org/10.1016/j.jhydrol.2013.06.012

36. Maliva, R. and Missimer, T., Arid Lands Water Evaluation and Management, Environmental Science and Engineering, Springer Berlin Heidelberg, Heidelberg, Germany, 2012, https://doi.org/10.1007/978-3-642-29104-3 
37. Song, L., Flux Decline in Crossflow Microfiltration and Ultrafiltration: Mechanisms and modelling of Membrane fouling, Journal of Membrane Science, Vol. 139, No. 2, pp 183-200, 1998, https://doi.org/10.1016/S0376-7388(97)00263-9 